\title{
Effect Of Enrichment And Empowerment On Competency In Improving Employee Performance
}

\author{
Bina Muwadah Rohma dan Mohammad Wasil \\ Program Studi Manajemen, Fakultas Ekonomi Dan Bisnis \\ Universitas Narotama Surabaya \\ Email author: mohammad.wasil@narotama.ac.id
}

\begin{abstract}
This study aims to analyze the effect of Enrichment and Empowerment on improving employee performance in Bn'D Control System Surabaya. The sample used is 40 respondents with quantitative research methods with data analysis using Path Analysis. The company always wants employee performance to contribute well, so the company needs to implement employee enrichment and empowerment programs. The results of this study indicate that Empowerment has a more positive and significant effect on employee performance. Meanwhile, Enrichment and Competence in the Bn'D Control System affect but not significantly on employee performance.
\end{abstract}

\section{Keyword:}

Enrichment, Empowerment, Competence, Employee Performance

\section{Pendahuluan}

Suatu Proses yang dilakukan dengan benar berpeluang besar untuk memperoleh hasil yang benar-benar baik. Dengan pemahaman seperti ini maka proses pengembangan dan pemberdayaan karyawan perlu dilakukan untuk mendapakan kinerja yang baik.

Sedangkan kinerja merupakan gambaran mengenai tingkat pencapaian pelaksanaan suatu program kegiatan atau kebijakan dalam mewujudkan sasaran, Visi dan Misi organisasi yang dituangkan melalui perencanaan strategis suatu organisasi Moeheriono, (2012) kinerja dapat diukur jika individu atau kelompok mempunyai kesamaan tugas dan tanggung jawab yang sama sebagai tolok ukur penilaian.

B'n D Control System Team merupakan team yang bergerak dibidang pengembangan hardware dan software. Pendirian team ini bertujuan untuk menjawab kebutuhan konsumen akan implementasi teknologi pada peralatan berwujud modul elektrik. Modul tersebut memadukan kemampuan kerja hardware dan software dan menerapkan teknologi mikrokontroller dan automatic control.

B'n D Control System Team dipimpin oleh seorang team leader. Dalam pelaksanaan tugasnya team leader dibantu oleh dua kepala departemen, yaitu kepala departemen hardware dan kepala depatermen software. Selain itu seorang team leader dibantu oleh seorang kepala marketing. Dibawah jajaran kepala departemen terdapat beberapa sub bagian kerja, yaitu kepala produksi, kepala pengadaan, dan sub divisi. Setiap bagian kerja dalam team Bn'D ControlSystem.

Team saling mendukung untuk memenuhi pelayanan pada konsumen Organisasi yang baik, tumbuh dan berkembang akan menitik beratkan pada sumber daya manusia (human resources) untuk menjalankan fungsi dengan optimal, khususnya dalam menghadapi dinamika perubahan yang terjadi di lingkungan. Dengan demikian kemampuan teknik, konseptual, moral, dari para pelaku perusahaan disemua tingkat pekerjaan sangat dibutuhkan selain itu kedudukan sumber daya manusia pada posisi yang paling tinggi berguna untuk mendorong perusahaan, periaku nilai dan keyakinan sebagai sarana penting dalam peningkatan kinerjanya.

Kinerja sebagai catatan terhadap hasil produksi dari sebuah pekerjaan tertentu atau aktifitas tertentu atau aktivitas tertentu dalam periode tertentu, menurut Gomes (1995) penilaian kinerja merupakan informasi yang sangat berharga untuk merencanakan dan mengambil keputusan tentang sumber daya manusia karena melalui penilaian kinerja perusahaan dapat memetakkan kualitas dari sumber daya manusia itu sendiri.

Pencapaian kinerja dengan standar yang baik dibutuhkan karekteristik-karakteristik tertentu pada diri seseorang baik internal maupun eksternal. Menurut Spencer dan Spencer (1993), kinerja berhubungan dengan kompetensi yaitu karakteristik mendasar pada individu yang memampukan individu bisa mencapai kinerja yang efektif dan atau superior dalam suatu pekerjaan atau kegiatan yang dilakukan individu (dalam hal ini kegiatan sebagai mahasiswa).

Kesesuaian kompetensi yang dimiliki oleh seseorang dengan kompetensi yang dibutuhkan oleh suatu pekerjaan maka akan semakin tinggi kinerja yang ditampilkannya dalam pekerjaan tersebut

Kinerja seorang karyawan bersifat individual, karena setiap karyawan mempunyai tinggkat kemampuan yang berbeda-beda dalam mengerjakan projek. 
Pada dasarnya setiap perusahaan akan berusaha untuk selalu meningkatkan kinerja karyawan demi tercapainya tujuan yang telah di tetapkan perusahaan. Untuk mencapai tujuan kinerja memerlukan karyawan yang memiliki kinerja yang baik. Kinerja yang di aktulisasikan karyawan juga di dukung oleh beberapa faktor dimana beberapa faktor ialah pengembangan (enrichment), dan pemberdayaan (empowerment).

Selain itu diperlukan pengelolaan yang baik bagi sumber daya manusia sebagai karyawan (aset perusahaan), agar dapat menghasilkan kinerja yang memberikan kontribusi secara efektif demi kemajuan perusahaan. Melalui interview pada Bn'D Control System pendahuluan dapat digambarkan dari permasalahan yang di dalam perusahaan, sebagai berikut:

1. Karyawan dalam mengerjakan tugas memiliki keterbatasan waktu sehingga jam kerja tidak efektif.

2. Pengembangan karir dirasa belum optimal,hal ini dapat dilihat dari hasil timbal balik karyawan terhadap pemberdayaan yang diberikan oleh perusahaan menurut manager perusahaan.

Walaupun program pemberian wewenang (empowerment) telah di lakukan namun permasalahan terkait dengan sumber daya manusia masih saja terjadi diperusahaan ini. Permasalahan pada perusahaan ini Selain itu Penilaian Kinerja yang belum pernah dilakukan didalam Bn'D Control System. Hal ini yang menyebabkan tidak dapat diketahuinya kinerja yang baik didalam perusahaan.

Berdasarkan survei, diketahui bahwa karyawan B'nD ControlSystem menyatakan setuju bahwa didalam perusahaan menyediakan materi yang berkaitan dengan pengembangan karir. Fenomena yang terdapat di dalam perusahaan ini yaitu adanya upaya untuk meningkatkan mutu kinerja melalui peningkatan keterampilan dan kualitas sumber daya manusia, seperti Pengembangan karyawan (Enrichment) dan Pemberdayaan karyawan (Empowerment) agar dapat bersaing dengan perusahaan sejenis lainya.

Penelitian ini ingin mengetahui lebih jauh mengenai kompetensi kerja karyawan Bn'd control system yang dapat meningkatkan kinerja karyawan. Pada perusahaan ini proram pengembangan (Enrichment) telah banyak di lakukan yaitu pelatihan dan pemeliharaan aset-aset sumber daya manusia dengan memberikan kesempatan melaksanakan sertifikasi pelatihan pengembangan program yan

Berdasarkan uraian diatas, diketahui bahwa Pengembangan (Enrichment) dan Pemberdayaan (Empowerment) adalah upaya perusahaan untuk meningkatkan kualitas kinerja yang baik.

\section{Tinjauan Pustaka}

\subsection{Enrichment (Pengembangan)}

Suparyadi (2015) pengembangan memiliki fokus pada memahami konsep dan konteks informasi, pengembangan pendapat : pengembangan kapasitas untuk menjalankan tugas, biasanya dilakukan dalam waktu yang lebih lama, sedangkan ukurannya adalah kualifikasi untuk melaksanakan tugas yang akan datang, peluang promosi dan keunggulan kompetitif peerusahaan di bidang sumber daya manusia.

Dessler (2014) pengembangan manajemen (management development) adalah segala usaha untuk meningkatkan kinerja manajerial dengan pengetahuan mengubah sikap atau meningkatkan keterampilan.

Noe et,al dkk (2010) pengembangan karir telah diuraikan secara tradisional, dengan berbagai cara. Pengembangan Karir telah didefinisikan sebagai urutan posisi yang dipegang pada pekerjaan. Ketika keahlian, pengalaman, dan kinerjanya meningkat, ia dapat bergerak melalui posisi penasihat rekayasa, perakayasa senior, dan teknisi senior.

\subsection{Empowerment (Pemberdayaan)}

Anastasia (2009) menyatakan bahwa pemberdayaan adalah bagian dari sebuah proses atau evolusi yang berjalan ketika entitas memiliki dua atau lebih orang dalam sebuah hubungan, secara personal atau profesional.

Said (2001) pemberdayaan mengandung makna adanya perubahan pada diri seseorang dari ketidak mampuan menjadi mampu, dari ketidak memiliki kewenangan menjadi memiliki tanggung jawab terhadap sesuatu yang di kerjakan.

\subsection{Kompetensi}

Suparadi(2015) Kompetensi yaitu perpaduan antara pengetahuan, keterampilan atau keahlian individu, hal ini yang dapat membuat individua tersebut mampu memenuhi apa yang disyaratkan oleh pekerja sehingga ia mampu melakukan pekerjaan dengan mencapai hasil yanng sesuai harapan.

Sunyoto (2012) Kompensasimerupakan suatu jaringan berbagai subproses untuk memebrikan balas jasa kepada karyawan untuk pelaksanaan pekerjaan dan untuk memotivasi karyawan agar mencapai tingkat prestasi yang diinginkan.

Undang-undang Ketenagakerjaan Nomor 13 Tahun 2003 : kompetensi kerja adalah kemampuan kerja setiap individu yang mencakup aspek Pengetahuan,Keterampilan, dan sikap kerja yang sesuai dengan standart yang ditetapkan. 


\subsection{Kinerja Karyawan}

Suparadi(2015)Manajemen kinerja adalah suatu upaya mengelolah kompetensi karyawan yang dilakukan oleh organisasi secara sistematik dan terus-menerus agar karyawan tersebut memiliki tingkat kinerja yang diharapkan oleh organisasi yaitu mampu memberikan kontribusi yang optimal sehingga mampu mencapai tujuan organisasi.

Kinerja karyawan yang umum untuk kebanyakan pekerjaan meliputi elemen sebagai berikut Mathis dan Jackson, (2009): kuantitas dari hasil, kualitas dari hasil, ketepatan waktu dari hasil,kehadiran,dan kemampuan bekerja sama

Mangkunegara (2009) memberikan pengertian bahwa kinerja adalah "hasil kerja secara kualitas dan kuantitas yang dicapai oleh seorang pegawai dalam melaksanakan tugasnya sesuai dengan tanggung jawab yang diberikan kepadanya".

Wibowo (2007) Manajemen kinerja adalah manajemen tentang menciptakan hubungan dan memastikan komunikasi yang efektif. Manajemen kinerja memfokuskan pada apa yang diperlukan oleh organisasi, manajer, dan pekerja untuk berhasil.

\section{Metode Penelitian}

\subsection{Populasi dan Sampel}

Berdasarkan informasi yang diterima melalui bagian admin diketahui bahwa sampel yang digunakan dalam penelitian ini adalah 40 karyawan yang diteliti, dimana pengambilan dalam sampel secara bertingkat (stratified random sampling), pada 15 teknisi , 3 operasional, 15 staff, dan 7 marketing.

\subsection{Definisi Operasional Variabel}

Berikut ini diuraikan definisi operasional variabel-variabel yang digunakan dalam penelitian ini. Definisi-definisi operasional variabel sebagai dasar pengukuran nilai konstruk dapat di lihat pada table :

Tabel 1 Definisi Operasional Variabel

\begin{tabular}{|c|c|c|}
\hline Variabel & Keterangan & Pengukuran \\
\hline $\begin{array}{l}\text { Enrichment } \\
\text { (Pengembangan) }\end{array}$ & $\begin{array}{l}\text { Program yang diberikan kepada karyawan dalam rangka untuk } \\
\text { mengevaluasi informasi tentang kemampuan diri sendiri yang } \\
\text { akan mempengaruhi pilihan dan upaya yang di lakukan untuk } \\
\text { menyelesaikan suatu pekerjaan }\end{array}$ & $\begin{array}{l}\text { Skala Likert } 1-5 \\
\text { dengan } 1 \text { (sangat tidak } \\
\text { setuju) sampai } 5 \\
\text { (sangat setuju) }\end{array}$ \\
\hline $\begin{array}{l}\text { Empowerment } \\
\text { (Pemberdayaan) }\end{array}$ & $\begin{array}{l}\text { Wewenang yang di berikan oleh perusahaan untuk dapat } \\
\text { mengambil keputusan menyelesaikan suatu pekerjaan. }\end{array}$ & $\begin{array}{l}\text { Skala Likert } 1-5 \\
\text { dengan } 1 \text { (sangat tidak } \\
\text { setuju) sampai } 5 \\
\text { (sangat setuju) }\end{array}$ \\
\hline Kompetensi & $\begin{array}{l}\text { kemampuan kerja setiap individu yang mencakup aspek } \\
\text { Pengetahuan,Keterampilan, dan sikap kerja yang sesuai dengan } \\
\text { standart yang ditetapkan }\end{array}$ & $\begin{array}{l}\text { Skala Likert } 1-5 \\
\text { dengan } 1 \text { (sangat tidak } \\
\text { setuju) sampai } 5 \\
\text { (sangat setuju) }\end{array}$ \\
\hline Kinerja & $\begin{array}{l}\text { Hasil kerja yang di capai seseorang dalam melaksanakan tugas } \\
\text { yang di bebankan kepadanya di dasarkan atas kecakapan, } \\
\text { pengalaman, kesungguhan dan waktu }\end{array}$ & $\begin{array}{l}\text { Skala Likert } 1-5 \\
\text { dengan } 1 \text { (sangat tidak } \\
\text { setuju) sampai } 5 \\
\text { (sangat setuju) }\end{array}$ \\
\hline
\end{tabular}

\subsection{Sumber Data dan Metode Pengumpulan Data}

Sumber data yang digunakan dalam penelitian ini adalah sumber data primer dan sekunder. Sumber data primer dalam penelitian ini diperoleh melalui penyebaran kuisioner kepada karyawan Bn'D Control System Surabaya. Data sekunder yang didapat berupa profil, visi, misi dan tujuan dari Bn'D Control System.

\subsection{Pengujian Instrumen Penelitian}

1. Uji Validitas.

Dianggap valid adalah nilai $r$ hitung $>$ dari nilai $r$ tabel. Uji validitas dilakukan dengan cara membandingkan $r$ hitung dengan $r$ tabel untuk degreee of freedom $(\mathrm{df})=\mathrm{n}-2$ dimana $\mathrm{n}$ adalah jumlah sampel, dengan tingkat signifikan uji satu arah sebesar 0.05 atau $5 \%$ jika $\mathrm{r}$ hitung $>\mathrm{r}$ tabel maka pertanyaan dikatakan valid.

2. Uji Reliabilitas.

Nilai cronbach alpha masing-masing variabel lebih dari $60 \%$ atau 0,6 maka penelitian ini dikatakan reliabel Ghozali (2001). 


\subsection{Teknik Analisis Data}

Metode analisis yang dipilih dalam penelitian ini untuk menganalisis data adalah dengan menggunakan analisis jalur. Alasan menggunakan path analysis jalur ini adalah karena dengan alat ini dapat dijelaskan bahwa hitungan antara variabel dan hubungandengan uji $\mathrm{F}$ dan uji $\mathrm{T}$ sebagai uji hipotesis.

\section{Hasil Penelitian Dan Pembahasan}

\subsection{Hasil Penelitian}

\subsubsection{Uji kualitas data}

1. Validitas data

Pengujian validitas kuesioner yang dilakukan Pearson Correlation. Berdasarkan hasil pengujian validitas diketahui dari tingkat signifikansi yang diperoleh keseluruhan indikator dari keempat variabel dan hasil tersebut menunjukkan nilai yang kurang dari 0,05 , yang berarti bahwa semua item pertanyaan yang digunakan dalam variabel kinerja karyawan telah valid.

2. Reliabilitas kuesioner

Pengujian reliabilitas kuesioner dilakukan dengan membandingkan hasil Cronbach's Alpha, berdasarkan hasil memiliki nilai pengolahan data menunjukkan bahwa semua item memiliki nilaiCronbach's Alpha yang lebih besar dari 0,6, yang artinya kuesioner tersebut konsisten.

Tabel 2 Hasi Uji Path Analisis Model 1

\begin{tabular}{ccccc}
\hline Variabel & Beta & $\begin{array}{c}\mathrm{T} \\
\text { hitung }\end{array}$ & Signifikan & Keterangan \\
\hline (Constant) & & 5,202 & 0,000 & Signifikan \\
Enrichment & 0,248 & 1,355 & 0,184 & Non Signifikan \\
Empowerment & 0,253 & 1,383 & 0,175 & Non Signifikan \\
F hitung & & & 4,649 & \\
Signifikansi F & & & 0,016 & \\
hitung & & & 0,448 & \\
$\mathrm{R}$ & & & 0,201 & \\
$\mathrm{R}^{2}$ & & & & \\
\hline
\end{tabular}

Kerangka hubungan kausal empiris antara X1, X2 dan X3 dapat dibuat persamaan struktur model 1 sebagai berikut :
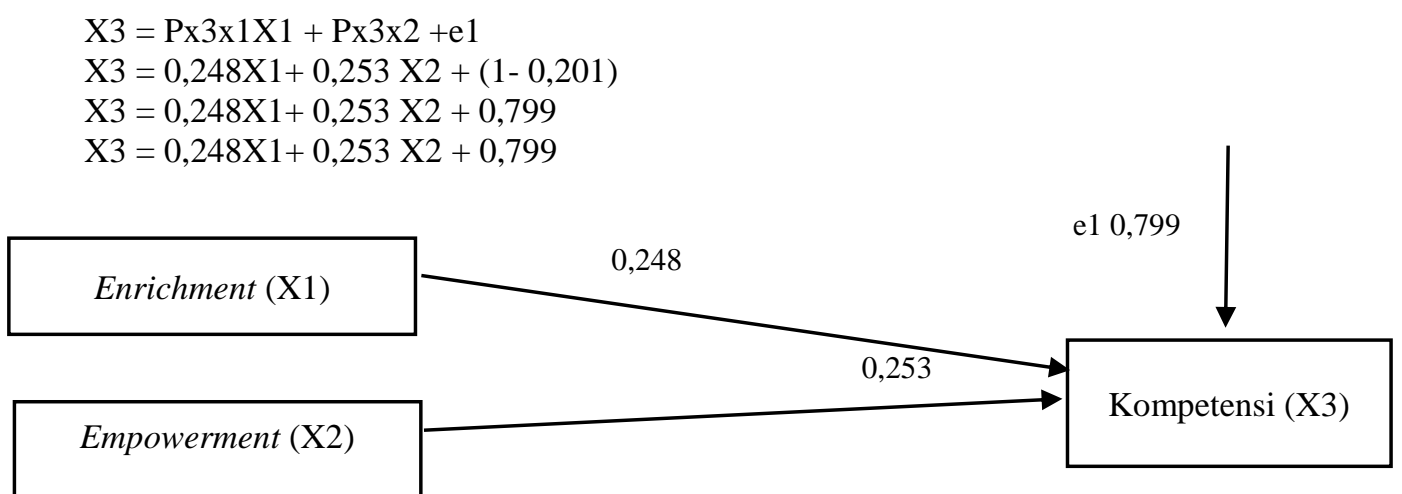

Gambar Hasi Uji Path Analisis Model 1 
Tabel 3 Hasi Uji Path Analisis Model 2

\begin{tabular}{|c|c|c|c|c|}
\hline Variabel & Beta & $\mathrm{T}$ hitung & Signifikan & Keterangan \\
\hline (Constant) & & 1,913 & 0,064 & $\begin{array}{c}\text { Non } \\
\text { Signifikan }\end{array}$ \\
\hline Enrichment & 0,248 & ,574 & 0,570 & $\begin{array}{c}\text { Non } \\
\text { Signifikan }\end{array}$ \\
\hline Empowerment & 0,572 & 3,509 & 0,001 & Signifikansi \\
\hline Kompetensi & 0,190 &, 188 &, 852 & $\begin{array}{c}\text { Non } \\
\text { Signifikan }\end{array}$ \\
\hline F hitung & & & 8,503 & \\
\hline Signifikansi F & & & 0,000 & \\
\hline hitung & & & 0,644 & \\
\hline $\begin{array}{c}\mathrm{R} \\
\mathrm{R}^{2}\end{array}$ & & & 0,415 & \\
\hline
\end{tabular}

Persamaan struktur model 2

sebagai berikut :

$$
\begin{aligned}
& Y=\text { Pyx } 1 X 1+\text { Pyx } 2+\text { Pyx } 3+e 1 \\
& Y=0,093 X 1+0,572 X 2+0,027 X 3(1-0,415) \\
& Y=0,093 X 1+0,572 X 2+0,027 X 3+0,585
\end{aligned}
$$

\begin{tabular}{|c|c|c|}
\hline Enrichment (X1) & & $\mathrm{e}_{2} 0,586$ \\
\hline Empowerment (X2) & 0,572 & Kinerja Karyawan \\
\hline Komnetensi (X3) & 0,027 & \\
\hline
\end{tabular}

\subsection{Uji T}

\subsubsection{Uji Hipotesis I}

Pengaruh Enrichment terhadap Kompetensi

$\mathrm{KD}$ parsial $=\beta \times 3 \times 1 \times$ zero order

$\mathrm{KD}$ parsial $=, 248 \times, 399$

KD parsial $=0,09852$ atau sama dengan $9,8 \%$

Memberikan pengaruh sebesar 9,8\% dengan tingkat signifikan sig 0,000 $<0,05$

Pengaruh Empowerment terhadap Kompetensi

$\mathrm{KD}$ parsial $=\beta \times 3 \times 2 \times$ zero order

$\mathrm{KD}$ parsial $=, 253 \mathrm{X}, 402$

KD parsial $=0,101706$ atau sama dengan $10,1 \%$

Pengaruh $10,1 \%$ signifikan karena nilai sig penelitian $0,000<0,05$.

\subsubsection{Uji Hipotesis 2}

Pengaruh Enrichment terhadap Kinerja karyawan

$\mathrm{KD}$ parsial $=\beta \mathrm{yx}_{1} \mathrm{X}$ zero order

$\mathrm{KD}$ parsial $=0,093 \mathrm{X} 0,446$

$\mathrm{KD}$ parsial $=0,041478$ atau sama dengan $4,1 \%$

Pengaruh Empowerment terhadap Kinerja karyawan

$\mathrm{KD}$ parsial $=\beta \mathrm{yx} \mathrm{X}$ zero order

$\mathrm{KD}$ parsial $=0,572 \mathrm{X}, 639$

$\mathrm{KD}$ parsial $=0,365508$ atau sama dengan $36,5 \%$

Pengaruh Kompetensi terhadap Kinerja karyawan

$\mathrm{KD}$ parsial $=\beta \mathrm{yx} \mathrm{X}$ zero order

KD parsial $=0,027 \mathrm{X}, 294$

$\mathrm{KD}$ parsial $=0,007938$ atau sama dengan $0,7 \%$ 


\subsection{Pengaruh parsial (tidak langsung)}

1.Penggaruh parsial Enrichment, kinerja melalui kompetensi.

$=0,093+(0,248 \times 0,294)$

$=0,093+0,072912$

$=0,172912$.

Besarnya pengaruh tidak langsung Enrichment terhadap kinerja karyawan melalui kompetensi adalah

0,172912 atau sebesar $17,2 \%$.

2. Penggaruh parsial Enrichment, kinerja melalui kompetensi.

$=0,093+(0,248 \times 0,294)$

$=0,093+0,072912$

$=0,172912$.

Besarnya pengaruh tidak langsung Enrichment terhadap kinerja karyawan melalui kompetensi adalah 0,172912 atau sebesar $17,2 \%$.

\subsection{Pembahasan}

Berdasarkan analisis data responden dengan beberapa uji sebagai berikut :

1. Variabel X1(Enrichment) secara parsial tidak berpengaruh secara signifikan terhadap Kompetensi.

2. Kontribusi langsung X1(Enrichment) terhadap Kompetensi adalah sebesar 9,8\%.

3. Variabel X2(Empowerment) secara parsial tidak berpengaruh secara signifikan terhadap Kompetensi.

4. Kontribusi langsung X2(Empowerment) terhadap Kompetensi adalah sebesar 10,1\%.

5. Variabel X1(Enrichment) secara parsial tidak berpengaruh secara signifikan terhadap Kinerja Karyawan.

6. Kontribusi langsung X1(Enrichment) terhadap Kinerja karyawan adalah sebesar 4,1\%.

7. Variabel X2(Empowerment) secara parsial berpengaruh secara signifikan terhadap Kinerja Karyawan.

8. Kontribusi langsung X2(Empowerment) terhadap Kinerja Karyawan adalah sebesar 36,5\%

9. Variabel X3(Kompetensi) secara parsial tidak berpengaruh secara signifikan terhadap Kinerja Karyawan.

10. Kontribusi langsung X3(Kompetensi) terhadap Kinerja Karyawan adalah sebesar 0,7\%.

\section{Penutup}

\subsection{Kesimpulan}

Dari hasil analisis path, menunjukkan bahwa variabel Enrichment berkontribusi secara langsung atau tidak langsung melalui kompetensi terhadap kinerja, akan tetapi tidak signifikan terhadap kinerja. Untuk variabel Empowerment berkontribusi secara langsung maupun tidak langsung melalui kompetensi secara signifikan.

Pengaruh variabel Enrichment berkontribusi secara langsung atau tidak langsung melalui kompetensi terhadap kinerja, akan tetapi tidak signifikan terhadap kinerja. Hal ini dikarenakan pengembangan karyawan hanya terfokus pada satu kasus, sedangkan kasus atau tugas yang diselesaikan didalam perusahaan IT memerlukan ide dan pengetahuan yang lebih.

Variabel Empowerment berkontribusi secara langsung maupun tidak langsung melalui kompetensi dengan yang signifikan, dikarenakan wewenang yang diberikan terhadap karyawan untuk memecahkan kasus atau masalah lebih menyukai jika karyawan diberikan kebebasan dengan cara tersendiri untuk menyelasaikan masalah, karena didalam Bn'D Control System diberlakukan sistem Based On Case atau penyelesaian berdasarkan tugas.

\subsection{Saran}

1. Enrichment atau Empowerment karyawan yang sudah dilakukan cukup baik, namun pengembangan dalam hal itu kurang mendukung dalam beberapa tugas. Dalam pengembangan karyawan sebaiknya lebih diperbanyak agar karyawan dalam menangani segala tugas.

2. Kompetensi yang ada dalam Bn'D Control System sudah baik, namun sebaiknya kompetensi menjadi standart mutu kinerja pada Bn'D Contro system untuk mempermudah dalam rekruitment serta penilaian kinerja karyawan.

3. Bagi peneiti selanjutnya, diharapkan dapat menambahkan variabel independen yang lain diluar Enrichment, Empowerment dan kompetensi agar memperoleh hasil yang lebih bervariasi dan dapat menggabarkan apa saja yang bisa mempengaruhi Kinerja Karyawan.

\section{Daftar Pustaka}

Gomes, Faustino Cardoso. 2003. Manajemen Sumber Daya Manusia. Grasindo. Jakarta

Spencer, M. L. and Spencer, M. S. 1993. Competence At Work: Models for Superior Performance. John Wiley and Sons Inc: New York 
Wibowo. 2007. Manajemen Kinerja. PT. Raja Grafindo Persada: Jakarta.

Mathis, Robert L., dan Jackson, John H. 2009. Manajemen Sumber Daya Manusia. Jakarta: Salemba Empat.

Ghozali,Imam. 2009. Analisis Multivariabel dengan program SPSS. Semarang : Badan Penerbit Universitas Diponegoro 